\title{
Experimental Investigation on Pool Boiling Heat Transfer to Formic Acid, Propanol and 2-Butanol Pure Liquids under the Atmospheric Pressure
}

\author{
M. M. Sarafraz \\ Department of Chemical Engineering, Mahshahr branch, Islamic Azad University, Mahshahr, Iran \\ †Email: mohamadmohsensarafraz@gmail.com
}

(Received November 16, 2010; accepted July 15, 2011)

\begin{abstract}
In this research, pool boiling heat transfer coefficient values were experimentally measured up to heat flux $115 \mathrm{~kW} . \mathrm{m}^{-2}$. Experiments were carried out for pool boiling of pure liquids, including of Formic acid, Propanol, 2-butanol on a horizontal smoothed cylinder, at atmospheric pressure. Applicability of the existing well-known and most common used correlations is comparatively discussed, with the present experimental data. The major predictions (over and/or under) were observed in some parameter range by the existing correlations. In this investigation the correlations of Stephan Abdelsalam, Boyko-Kruzhilin and Mostinski, have been compared with experimental data.
\end{abstract}

Keywords: Pool boiling, Heat transfer coefficient, Pure liquids, Experimental data, Dimensional analysis

\section{NOMENCLATURE}

\begin{tabular}{|c|c|}
\hline A & area, $\mathrm{m} 2$ \\
\hline $\mathrm{b}_{0}$ & $\begin{array}{l}\text { ratio of the interfacial area of heat transfer to } \\
\text { the interfacial area of mass transfer }\end{array}$ \\
\hline $\mathrm{C}$ & 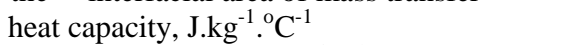 \\
\hline $\mathrm{D}_{\mathrm{AB}}$ & diffusivity coefficient, $\mathrm{m}^{2} \cdot \mathrm{s}^{-1}$ \\
\hline $\mathrm{D}_{\mathrm{b}}$ & bubble departing diameter, $\mathrm{m}$ \\
\hline $\mathrm{F}_{\mathrm{P}}$ & see Gorenflo equation \\
\hline $\mathrm{Fq}$ & see Gorenflo equation \\
\hline $\mathrm{F}_{\mathrm{WM}}$ & see Gorenflo equation \\
\hline $\mathrm{F}_{\mathrm{WR}}$ & see Gorenflo equation \\
\hline G & gravitational acceleration, $\mathrm{m} 2 . \mathrm{s}^{-1}$ \\
\hline$\Delta \mathrm{H}_{\mathrm{fg}}$ & heat of vaporization, $\mathrm{j} \cdot \mathrm{kg}^{-1}$ \\
\hline $\mathrm{K}^{\mathrm{T}}$ & thermal conductivity, W. $\mathrm{m}^{-1} \cdot{ }^{\circ} \mathrm{C}^{-1}$ \\
\hline $1^{*}$ & see Boyko-Kruzhilin equation \\
\hline $\mathrm{n}$ & see Gorenflo equation \\
\hline $\mathrm{N}$ & number of components \\
\hline Gre & yymbols \\
\hline
\end{tabular}

\section{INTRODUCTION}

Pool boiling of pure liquids is included in many industrial processes and chemical and petrochemical applications such as distillation, refrigeration and power cycles. Design, operation and optimization of the involved

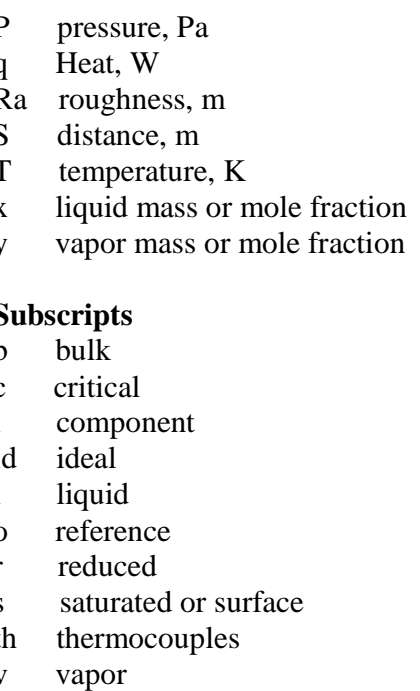

equipment require an accurate understanding of the boiling heat transfer and heat transfer mechanisms between surface and the boiling liquid. Many researches of pool boiling through the few decades were done to survey on fundamental Mechanisms of pool boiling. Due to the complication of the boiling phenomena as well as 
unknown interactions between a numbers of subprocesses, real facts about boiling are still unknown. Additionally, side processes are including nucleation problems, capillary, buoyancy and viscous forces implicated in bubble dynamics, evaporation associated with mass transfer in mixtures boiling, conduction and convection heat transfer mechanisms and also the Marangoni effect Alavi Fazel and Roumana (2006). Also, mutual interactions including interaction between bubbles and heating surface and also between neighbouring nucleation site plays significant role in boiling heat transfer coefficient. At very high heat fluxes, radiation heat transfer has also a contribution in the total heat transfer, which is not discussed here. The structure of heat transfer surface may be rigorously complicated and may contain nucleation cavities with various shapes and sizes. Practically, micro- surface information is not fully available for any given heating surface, which has significant role in determination of boiling heat transfer. There are many predictive Correlations for boiling heat transfer coefficient for pure liquids. These correlations are generally empirical or Semi -empirical. Comparisons between existing correlations as a function of heat flux presents. In this article, the major predictive correlations for pool boiling heat transfer have been briefly reviewed. The experimental results have been correlated to the predictive correlations. Finally, a new empirical correlation has been proposed, which provides better accuracy in compare to other existing correlations Alavi Fazel and Roumana (2006).

\section{Literature REVIEW}

Vinayak-Balakrishna Vinayak Rao and Balakrishnan (2004) has a wide-ranging survey on some correlations including Gorenflo (1993), Stephan and Abdelsalam (1980). and McNelly (1953) for pure boiling liquids. The applicability and constancy of some other correlations such as Boyko-Kruzhilin (1976) and Mostinski (1963) could be found in some other references Taboas. The major existing correlations for pure boiling systems are summarized in Table 1. As a rule, each correlation has some conflicting advantages and disadvantages. Among this complexity, Gorenflo Gorenflo (1993) has a major distinction in compare to other exiting correlations with two tuning parameters. These tuning parameters are already found for many different pure boiling systems. These tuning parameters could also be empirically determined. Sarafraz (2012) recently has redeveloped a correlation for estimating the pool boiling heat transfer coefficient of pure and binary mixtures.

\section{EXPERIMENTAL APPARATUS \& Procedure}

Figure. 1 presents schematically the experimental equipment used in the present measurements. This boiling vessel is a vertical hollow cylinder of stainless steel containing approximately 30 liters of test liquid connected to a vertical condenser to condense and recycle the evaporated liquid. The whole system is heavily isolated for more controllability and reduction of the heat loss. The temperature of the liquid inside the tank is constantly monitored and controlled to any predetermined set point by a thermal regulator which is involving the thermocouples to an appropriate band heater covering the outside of the tank. The pressure of the system is monitored and regulated continuously. A safety pressure relief valve is also installed to prevent any danger situation. The test section is a horizontal rod heater with a diameter of $21 \mathrm{~mm}$ and a heating length of $105 \mathrm{~mm}$, which can be observed and photographed through observation glasses. This heater consists of an internally heated stainless steel sheathed rod and four stainless steel sheathed thermocouples which are entrenched along the circumference of the heater, close to the heating surface. Some details of the rod heater are given in Fig. 2. One thermocouple inside the rod heater was used as a protection trip, to cut off the electric power if the temperature exceeds the maximum limit. A PC-based data acquisition system was used to record all measuring parameters. The input power to the rod heater is precisely equal to the heat flux and could be calculated by the product of electrical voltage, current and cosine of the difference between electrical voltage and current. The average of five readings was used to determine the difference between heating surface and the bulk temperature of each thermocouple. To calculate the real surface temperature by correcting the minor temperature drop due to the small distance between surface and thermocouple location, the Furriers' conduction equation is used as follow:

$T_{s}-T_{b}=\left(T_{t h}-T_{b}\right)-(s / k)(q / A)$

In this equation, $s$ is the distance between the thermocouple location and heat transfer surface and $k$ is the thermal conductivity of the heater material. The value of $s / k$ is determined for each thermocouple by calibration of the test heater. The average temperature difference was the arithmetic average of the four thermocouple locations. The boiling heat transfer coefficient $\alpha$ is calculated by following equation:

$$
\alpha=\left[\frac{q / A}{\left(T_{s}-T_{b}\right)}\right]
$$

For each experiment, picture of boiling phenomena was taken using a high speed camera. In explaining of experimental procedure, the entire system including the rod heater and the inside of the tank were cleaned and the test solution was introduced. The vacuum pump is then turned on and the pressure of the system is kept low approximately to $10 \mathrm{kPa}$ for five hour to allow all the dissolved gases especially the dissolved air has been stripped from the test solution. Following this, the tank band heater was switch on and the temperature of the system allowed rising to the saturation temperature. This procedure presents a homogeneous condition right through. Then the electric power was slowly supplied to the rod heater and increased gradually to a constant predetermined value. Data acquisition was simultaneously switched on to record the required parameters including the cylinder surface temperature, 
M. M. Sarafraz / JAFM, Vol. 6, No. 1, pp. 73-79, 2013.

bulk temperature, heat flux and also all visual information. All experimental runs were carried out with decreasing heat flux to eliminate the hysteresis effect. Some runs were repeated twice and even more than three times to ensure the reproducibility of the experiments.

Table 2 presents the ordinary physical constants of Test liquids and also, table 3 represent some important physical properties of test liquids during experiments.

Table1 Major available correlations for predicting the pool boiling heat transfer coefficient to pure liquids

\begin{tabular}{|c|c|}
\hline Mostinsky (1963) & $\alpha=(3.59 E-5) P_{c}^{0.69} \cdot q^{0.7} \times\left(1.8 \times\left(\frac{P}{P_{c}}\right)^{0.17}+4 \times\left(\frac{P}{P c}\right)^{1.2}+10 \times\left(\frac{P}{P c}\right)^{10}\right.$ \\
\hline Mc-Nelly (1953) & $\alpha=0.225 \times\left(\frac{C_{p l} \cdot q}{H_{f g}}\right)^{0.69}\left(\frac{P k_{l}}{\sigma}\right)^{0.31}\left(\frac{\rho_{l}}{\rho_{v}}-1\right)^{0.33}$ \\
\hline Labantov (1972) & $\alpha=0.075 \times\left[1+10\left(\frac{\rho v}{\rho_{l}-\rho_{v}}\right)^{0.67}\right]\left[\frac{k_{l}^{2}}{v \sigma\left(T_{s}+273.15\right)}\right]^{0.33} . q^{0.67}$ \\
\hline $\begin{array}{l}\text { Boyko-Kruzhilin } \\
\text { (1967) }\end{array}$ & $\begin{array}{l}\alpha=0.082 \times \frac{k_{l}}{l^{*}}\left[\frac{H_{f g} q}{g\left(T_{s}+273.15\right) K_{l}} \cdot\left(\frac{\rho_{v}}{\rho_{l}-\rho_{v}}\right)\right]^{0.7}\left[\frac{\left(T_{s}+273.15\right) C_{p l} \sigma P}{H_{f g} \rho_{v} l *}\right. \\
l^{*}=\left[\frac{\sigma}{g\left(\rho_{l}-\rho_{v}\right)}\right]^{0.5}\end{array}$ \\
\hline Kutateladze (1990) & $\begin{array}{l}\alpha=\left[(3.37 \times E-9) \cdot\left(\frac{K_{l}}{l^{*}}\right)\left(\frac{H_{f g}}{C_{p} q}\right)^{-2} \cdot M_{*}^{-4}\right]^{0.33} \\
M_{*}^{-4}=\frac{(P / \rho v)^{2}}{(\sigma g) /\left(\rho_{l}-\rho_{v}\right)}\end{array}$ \\
\hline $\begin{array}{l}\text { Stephan-Abdelsalam } \\
\text { (1980) }\end{array}$ & $\alpha=0.23 \frac{K_{l}}{d_{b}}\left(\frac{q d_{b}}{k_{l} T_{s}}\right)^{-0.74}\left(\frac{\rho_{v}}{\rho_{l}}\right)^{0.297}\left(\frac{H_{f g} d_{b}^{2}}{\hat{\alpha}^{2}}\right)^{0.371}\left(\frac{\hat{\alpha}^{2} \rho_{l}}{\sigma d_{b}}\right)^{0.35}\left(\frac{\rho_{l}-\rho_{v}}{\rho_{l}}\right)^{-1.73}$ \\
\hline Nishikawa(1982) & $\alpha=\frac{31.4 . P c^{0.2}}{M W^{0.1} T_{c}^{0.9}}\left(8 R_{p}\right)^{0.2\left(1-\mathrm{P}_{\mathrm{r}}\right)} \cdot \frac{\left(\operatorname{Pr}^{0.23}\right) q^{0.8}}{\left(1-0.99 \mathrm{P}_{\mathrm{r}}\right)^{0.9}}, R_{p}=0.125 \mu m$ \\
\hline
\end{tabular}

Table 2 Some physical properties of selected test liquids

\begin{tabular}{|c|c|c|c|c|}
\hline Physical property & Formic Acid & Propanol & 2-butanol & Units \\
\hline Molecular weight & 46.025 & 60.096 & 74.12 & g.gmol $^{-1}$ \\
\hline Normal boiling point $\left[\mathrm{C}^{\circ}\right]$ & 100.55 & 97.177 & 99.796 & ${ }^{\circ} \mathrm{C}$ \\
\hline Critical pressure $[\mathrm{kPa}]$ & 5500000 & 5170000 & 4170000 & $\mathrm{~Pa}$ \\
\hline
\end{tabular}




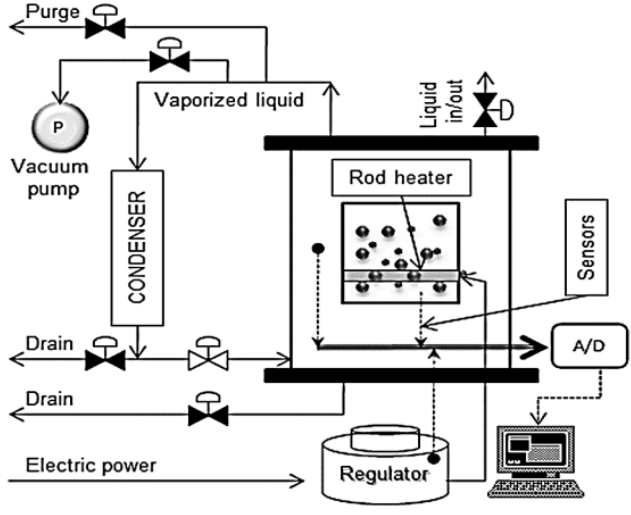

Fig. 1. A scheme of the experimental apparatus

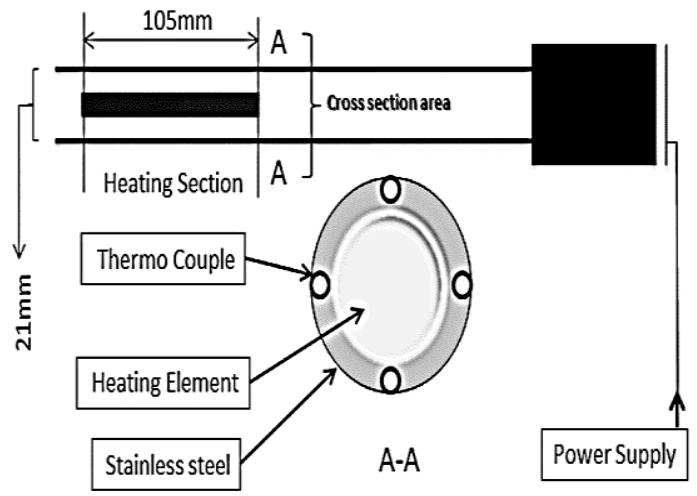

Fig. 2. Some details of heating section

Table 3 Important physical properties of tested liquids

\begin{tabular}{|c|c|c|c|}
\hline Physical property & Formic acid & Propanol & 2-Butanol \\
\hline Alpha, $\alpha\left[\mathrm{m}^{2} . \mathrm{S}^{-1}\right]$ & 9.72 & 5.35 & 4.61 \\
\hline Bulk temperature $\left[\mathrm{C}^{\circ}\right]$ & 100.55 & 97.177 & 99.796 \\
\hline Liquid density $\left[\mathrm{kg} \cdot \mathrm{m}^{-3}\right]$ & 1053 & 710.43 & 726.51 \\
\hline Vapor density[ kg. m$\left.{ }^{-3}\right]$ & 3.0043 & 3.032 & 3.0098 \\
\hline Surface tension $\left[\mathrm{dyne} . \mathrm{m}^{-1}\right]$ & 0.020375 & 0.017334 & 0.01443 \\
\hline Liquid thermal cond. $\left[\mathrm{w} \cdot \mathrm{m}^{-1} \cdot \mathrm{c}^{-1}\right]$ & 0.16297 & 0.12613 & 0.1135 \\
\hline Liquid heat capacity $\left[\mathrm{j} \cdot \mathrm{kg}^{-1} \cdot \mathrm{c}^{-1}\right]$ & 1585.4 & 3315.4 & 3093.4 \\
\hline Heat of vaporization[ $\left.\mathrm{j} \cdot \mathrm{kg}^{-1}\right]$ & 478960 & 550620 & 695720 \\
\hline
\end{tabular}

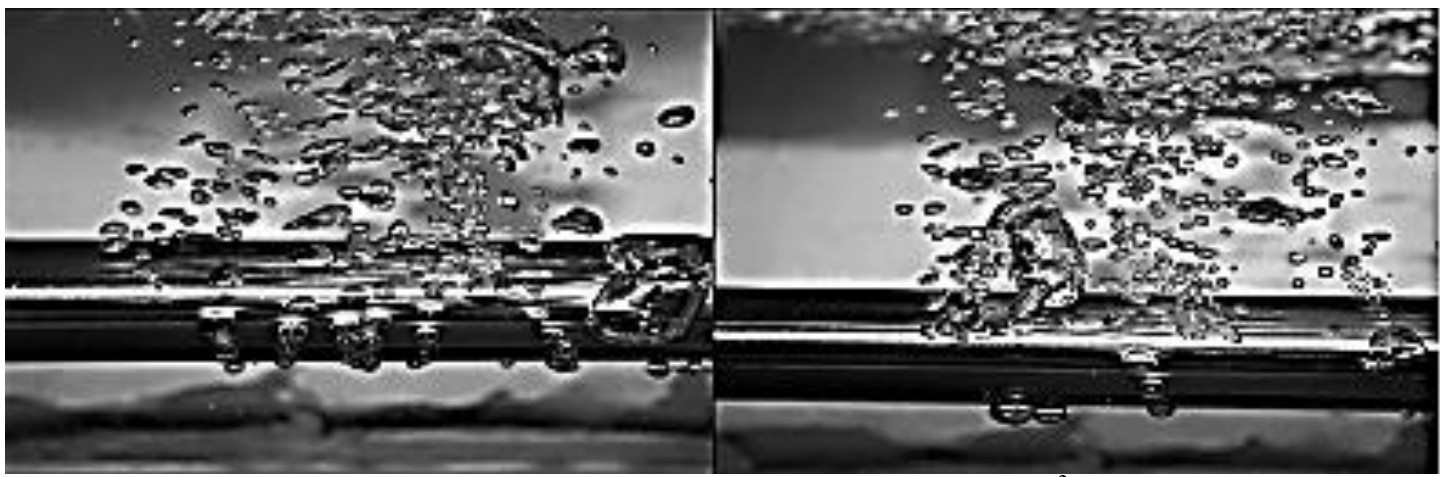

Fig. 3. Pool boiling of formic acid in 10 and $60 \mathrm{~kW} \cdot \mathrm{m}^{-2}$

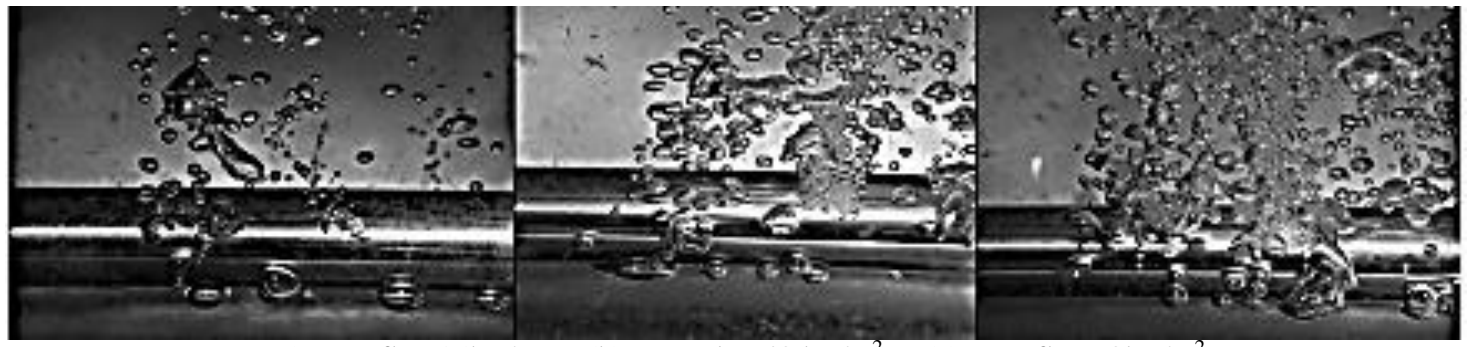

$\begin{array}{lll}\text { a) Heat flux } 15 \mathrm{kw} / \mathrm{m} & \text { (b) Heat Flux } 40 \mathrm{kw} / \mathrm{m}^{2} & \text { (c) Heat flux } 90 \mathrm{kw} / \mathrm{m}^{2}\end{array}$

Fig. 4. Pool boiling of 2-Butanol under the atmospheric pressure 


\section{RESUlts AND DiscuSSION}

Experimental data have shown that increasing heat flux results in increasing the average number of nucleation site density as well as the rate of bubble formation. However, it was not possible to count the number of NSD at high heat flux due to the extreme turbulences and agitations. Additionally by increasing of heat flux, values of heat transfer coefficient have clearly increased. This increasing is linearly considered with direct heat flux variations. Fig.6 typically represents the experimental data of the pool boiling heat transfer for all the test liquids. Based on the graph details, by increasing the heat flux, the boiling heat transfer coefficient strongly increases for all test liquids. There are a few fluctuations, which are principally related to the experimental error and also hysteresis effect. Note that the performance of A/D (Analogue to Digital converter) is sensitive to the ambient condition.

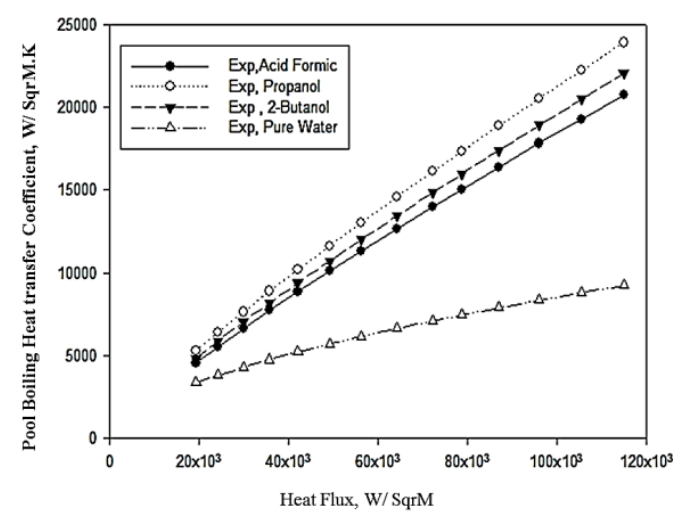

Fig. 5. Experimental data for test liquids and pure water

However, all the boiling points are in a same level (close to $100 \mathrm{C}^{\circ}$ ) but deviations of water in comparison with experimental data are higher relative to the test liquids. Comparison between existing correlations for estimating the heat transfer coefficient such as Stephan-Abdelsalam or McNelly demonstrates that experimental results have a good agreement with results of calculations. In addition, there were some deviations between correlations which are almost rational due to the approximate of physical properties and because of the experimental errors through the experiments. Figs (6-8) show the comparison between the experimental data and those of calculated by correlations.

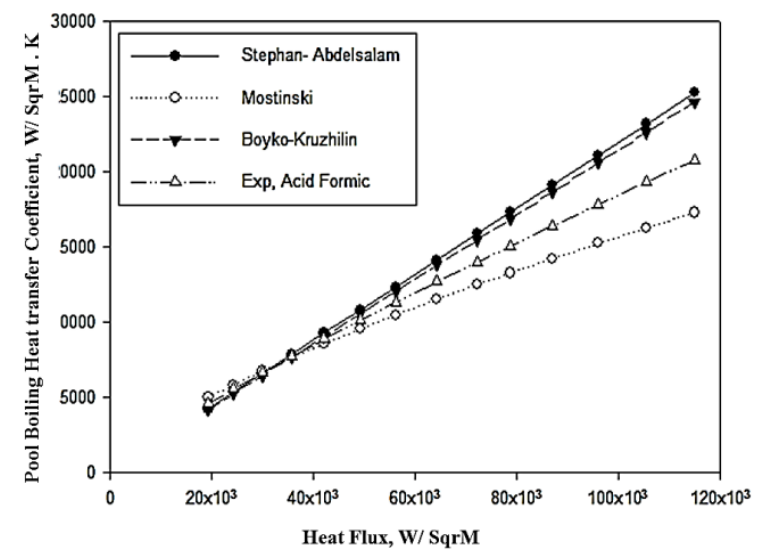

Fig. 6. Comparison of experimental data with results of other correlations for Formic acid

As Seen in Fig.7 experimental data are just approximately placed in amidst of the Mostinsky and Boyko-Kruzhilin correlations.

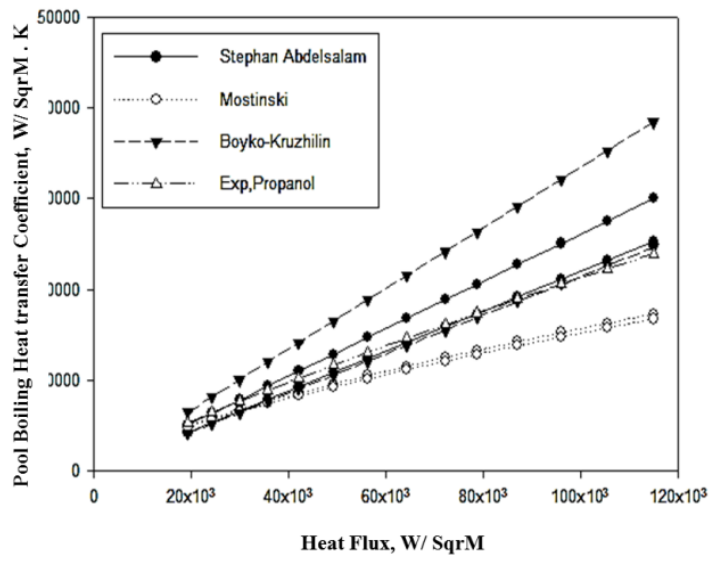

Fig. 7. Comparison of experimental data with results of other correlations for Propanol

Values of deviations of each correlation in comparison with experimental data are shown in table 4.

Table 4 value of deviations ADD \% of correlations from experimental data

\begin{tabular}{|c|c|c|c|c|c|c|}
\hline Correlation & $\begin{array}{c}\text { Stephan- } \\
\text { Abdelsalam } \\
(1980)\end{array}$ & $\begin{array}{c}\text { Mc-Nelly } \\
(1953)\end{array}$ & $\begin{array}{c}\text { Mostinsky } \\
(1963)\end{array}$ & $\begin{array}{c}\text { Boyko- } \\
\text { Kruzhilin } \\
(1967)\end{array}$ & $\begin{array}{c}\text { Labantov } \\
(1972)\end{array}$ & $\begin{array}{c}\text { Fujita }^{*} \\
(1982)\end{array}$ \\
\hline Formic Acid & $9.137 \%$ & $35.59 \%$ & $6.65 \%$ & $7.54 \%$ & $98 \%$ & $86 \%$ \\
\hline Propanol & $12.56 \%$ & $43.31 \%$ & $21.58 \%$ & $8.2 \%$ & $105 \%$ & $78 \%$ \\
\hline 2-butanol & $10.87 \%$ & $59.96 \%$ & $23.87 \%$ & $11.88 \%$ & $93 \%$ & $91 \%$ \\
\hline
\end{tabular}




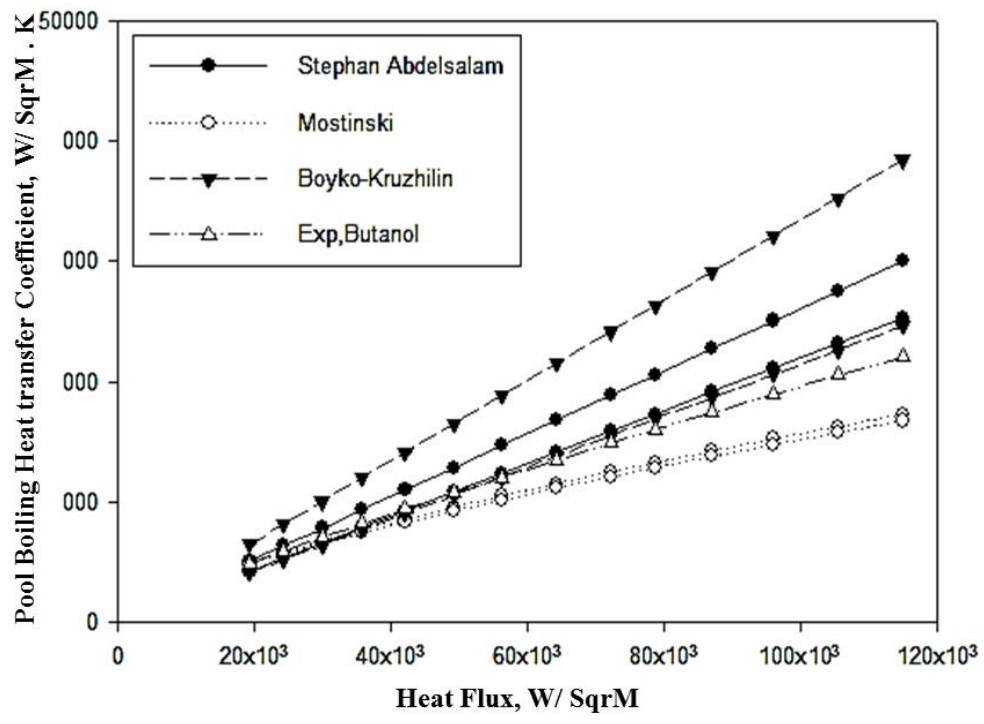

Fig. 8. Comparison of experimental data with other correlation for Butanol

* It should be noticed that star-marked correlations had very deviation in comparison with experimental data, furthermore were not plotted in Figs 7-9.

A.D.D $\%=\frac{\text { Estimated Value From Correlation }- \text { Experimental Data }}{\text { Experimental Data }} \times 100 \%$

\section{NEW EMPIRICAL MODEL}

Alavi Fazel et al. proposed a semi empirical using dimensional analysis method for some pure liquids Alavi Fazel and Roumana (2006). In this work, using the curvefitting soft wares such as Systat ${ }^{\mathrm{TM}}$, Sigma plot and Table curve as well as the dimension analysis of all the possible dimensionless groups have been obtained. The influence of parameters including the saturation temperature, critical pressure, liquid and vapor thermal conductivities, viscosities, heat capacities, densities also boiling heat fluxes, surface tensions and heat of evaporations were considered during modeling. This means eleven influencing parameter with five dimensions including: $\mathrm{Q}$, $\mathrm{L}, \mathrm{T}, \theta$ and $\mathrm{M}$ which are related to heat, length, temperature, time and mass respectively. Based on the Dimensionless Buckingham theory, the following dimensionless numbers can be correlated with least error:

$$
\begin{gathered}
A^{0}=\left[\frac{K \cdot D_{A B} \cdot T_{s}}{\rho \cdot C \cdot \sigma \cdot \Delta H_{f g}}\right]^{\alpha} \\
A^{1}=\left[\frac{q \cdot D_{A B}}{\sigma \cdot \Delta H_{f g}}\right]^{\beta}
\end{gathered}
$$

In these dimensionless numbers, $\mathrm{D}_{\mathrm{AB}}$ is molecular diffusion and $\sigma, \Delta H_{f g}$ are surface tension and enthalpy of vaporization respectively. Amount of $\alpha, \beta$ in present study equals to 0.98973 and 0.9956 respectively. By considering this assumption that:

$$
A^{1}=a \cdot A^{\stackrel{b}{0}}
$$

Moreover, separately, a, b as a tuning parameters are found equal to 3.0219 and 0.8045 respectively

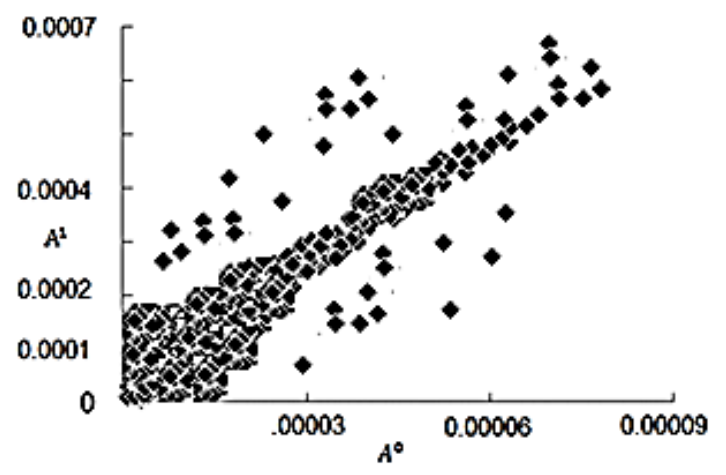

Fig. 9. Correlation between $A^{0}, A^{l}$

So the better, appropriate correlation for estimating pool boiling heat transfer coefficient in tested liquids has been achieved as:

$\alpha=\frac{3.0219 \times \sigma^{0.12} \Delta H_{f g}^{0.1107} q^{0.8045}}{T_{s} \cdot D_{A B}^{0.1398}}$ 


\section{CONCLUSion}

Pool boiling heat transfer coefficients for various pure liquids including water, Formic acid, Propanol, 2-Butanol have been experimentally measured at atmospheric pressure. The major Predicting correlations for boiling heat transfer in pure liquids have been briefly reviewed. A comparison between experimental data and the Famous existing correlations presents a significant error. In this Investigation, based on the experimental results, for pure acid formic Mostinski correlation predicts heat transfer coefficient more precisely than other correlations. For pure Propanol Boyko-Kruzhilin and for pure 2-butanol, Stephan-abdelsalam is the most precise correlation than others. In this investigation, based on the dimensional analysis, two new dimensionless groups have been generated which can relate the pool boiling heat transfer coefficient to the physical properties of boiling liquids. The new correlation presents better accuracy in compare to other existing correlations.

\section{ACKNOWLEDGMENT}

Author wishes to appreciate Dr. S. A. Alavi Fazel for his scientific supports and great ideas.

\section{REFERENCES}

Alavi Fazel, S.A., Roumana R., (2006). Int. Conf. on Continuum Mechanics Fluids Heat WSEAS, Mechanical Engineering Series of Reference Books and Textbooks

Boyko-Kruzhilin, (1967). Inernational Journal of Heat Mass Transfer, (10), 361.

Fritz, W. (1935), Berechunung des maximal volumens von Damp fblasen, Phys.2, (36), 379-384.
Gorenflo, D. (1993).Pool boiling, VDI Heat Atlas Chapter boiling.

Kutateladze, S.S., (1990), Heat Transfer and Hydrodynamic Resistance:Handbook

Labuntsov, D.A, (1972).Heat transfer problems with nucleate boiling of liquids, Thermal Eng.(19), 2128.

Mcnelly, M.J. (1953), A correlation of rates of heat transfer to nucleate boiling of liquids, J. Imperial College Chem. Eng. Soc, (7), 18-34.

Mostinski, I.L. (1963), Application of the rule of corresponding states for calculation of heat transfer and critical heat flux, Teploenergetika, (4), 66.

Nishikawa, K., Fujita, Y., Ohta, H., Hidaka, (1982), Effect of the surface roughness on the nucleate boiling heat transfer over a wide range of pressure, Proceedings of the 7th International Heat Transfer Conference München, (Germany), (4), 1-66.

Stephan, K., Abdelsalam, K. (1980). Heat transfer correlation for natural convection boiling, International Journal of Heat and Mass Transfer, (23), 73-87.

Taboas, F., Valle`s, M., Bourouis, M., Coronas, A., Vinayak Rao, G., Balakrishnan, A. R. (2004). Heat transfer in nucleate pool boiling of multicomponent mixtures, Experimental Thermal and Fluid Science, (29), 87-103.

Sarafraz, M. M., (2012). Nucleate pool boiling of aqueous solution of citric acid on a smoothed horizontal cylinder. Heat and Mass Transfer, (48), 611-619. 